\title{
LA PERSPECTIVA DE GÉNERO \\ EN EL NUEVO CÓDIGO PENAL DE HONDURAS
}

Anny L. Matamoros Pineda ${ }^{1}$

DOI: https://doi.org/10.5377//rd.v41i1.10493

\section{RESUMEN}

En Honduras, un quinto Código Penal entró en vigor el 25 de junio de 2020. Entre sus novedades se encuentra, el principio de legalidad en el que se incorpora el criterio de género como regla de interpretación. Igualmente, retoma la discriminación por razones de género en el catálogo de circunstancias agravantes. Estas incorporaciones son favorables teniendo en cuenta que Honduras es uno de los países con la tasa de femicidios más alta de la región latinoamericana y, además, es suscriptor de importantes obligaciones y compromisos en la materia. No obstante, al constituirse el género por los roles, atributos y comportamientos otorgados por la sociedad a hombres y mujeres, el derecho en general debe ser considerado como producto, reproductor y productor de género. En ese sentido, es indispensable analizar la nueva normativa penal aprobada a la luz de los desarrollos doctrinales en la materia, con el propósito de determinar, si la inclusión de estos elementos es suficiente para afirmar que el nuevo Código Penal cuenta con una perspectiva de género.

\section{PALABRAS CLAVE:}

Género, criterio de género, Código Penal, Derecho Penal, violencia contra la mujer.

Fecha de recepción:27 de Agosto de 2020 Fecha de aprobación:06 de noviembre de 2020

1 Máster en Derecho Penal y Procesal Penal, Universidad Nacional Autónoma de Honduras. Máster en Derecho Constitucional, Universidad de Valencia. Abogada egresada de la Universidad Católica de Honduras (UNICAH).

Correo electrónico: annymatamorosp.8@gmail.com 


\title{
GENDER PERSPECTIVE \\ IN THE NEW CRIMINAL CODE OF HONDURAS
}

Anny L. Matamoros Pineda*

DOI: $\underline{\text { https://doi.org/10.5377/Ird.v41i1.1049 }}$

\begin{abstract}
In Honduras a fifth Criminal Code entered into force on June 25, 2020. Among its innovations is the inclusion of the gender criteria in the principle of legality as a rule of interpretation, as well as the incorporation of the discrimination for reasons of genders among the aggravating circumstances. These inclusions are favorable taking into consideration that Honduras is one of the countries with the highest rates of femicide in the Latin-American region and also guarantor of obligations and compromises in the subject. However, due to the fact that gender is conform by the roles, attributes and behaviors given by society to men and women, law in general becomes a product that at the same time reproduce and produce gender. In that sense, is an imperative to analyze the approved Criminal Code in light of the doctrinal developments in the subject, with the purpose of determine if the inclusion of these elements is enough to affirm that this new criminal law framework has a gender perspective.
\end{abstract}

\section{KEYWORDS:}

Gender, gender criteria, Criminal Code, Criminal Law, violence against women

Date received: August 27, 2020 Approval date: November 06, 2020

\footnotetext{
* Master in Criminal Law and Criminal Procedure, Universidad Nacional Autonoma de Honduras. Master in Constitutional Law, Universidad de Valencia. Lawyer graduated from the Unviversidad Catolica de Honduras (UNICAH).

Email: annymatamorosp.8@gmail.com
} 


\section{INTRODUCCIÓN}

El nuevo Código Penal fue aprobado en un contexto en el que subyacen diversos desafíos para el Estado de Honduras, entre ellos, la prevención y erradicación de la violencia contra las mujeres, por constituir un fenómeno social de alto impacto en la sociedad hondureña ${ }^{2}$. Honduras como Estado signatario de instrumentos internaciones en la materia como, la Convención de Interamericana Para Prevenir, Sancionar y Erradicar la Violencia contra la Mujer (en adelante Convención De Belem Do Para) y la Convención sobre la eliminación de todas las formas de discriminación contra la mujer (en adelante CEDAW), ha asumido entre otros compromisos, remover los obstáculos en esta materia a través de la adopción de leyes y políticas públicas encaminadas a la prevención, erradicación y sanción de la violencia contra las mujeres.

Uno de los mecanismos más utilizados por los Estados para cumplir con dicho compromiso, es la aplicación de la ley penal para sancionar las conductas de violencia contra las mujeres. En ese sentido, el artículo 1 del Código Penal relacionado al principio de legalidad, incorpora el criterio de género como regla de interpretación. Asimismo, el artículo 32 numeral 8 incorpora la discriminación por razones de género en el catálogo de circunstancias agravantes.

2 De acuerdo con el Observatorio de Muertes Violentas de Mujeres y Femicidios del Instituto Universitario en Democracia, Paz y Seguridad (en adelante IUDPAS), durante el 2018 se registraron 383 muertes violentas de mujeres, lo que equivale a un promedio de 32 víctimas mensuales y una muerte cada 22 horas con 30 minutos. Por su parte, el Observatorio de Igualdad de Género de América Latina y el Caribe de la Comisión Económica para América Latina y el Caribe (en adelante CEPAL), en 2018 ubicó a Honduras como uno de los países, con la tasa de femicidios más alta en la región con 5.1 por cada 100.000 mujeres.
De esta manera, se debe entender a la luz de los desarrollos teóricos y doctrinarios, la concepción de género inserta en el Código Penal, bajo el entendido que el derecho es "producto, reproductor y productor de género", moldeando con ello las relaciones entre hombres y mujeres. Lo anterior, con el propósito de determinar, si la inclusión del criterio de género como regla de interpretación y la discriminación por razones de género como circunstancia agravante son suficientes para afirmar que el nuevo Código Penal cuenta con un enfoque de género.

\section{METODOLOGÍA}

Para realizar dicho análisis se utiliza el método deductivo bajo las técnicas y el enfoque de tipo descriptivo, normativo y propositivo. En el tema objeto de estudio, se analiza desde una perspectiva teórica la noción de género, la concepción del derecho como generador de género y las posiciones feministas sobre la intervención del Derecho Penal como mecanismo de respuesta para resolver la problemática de violencia contra las mujeres. A partir del enfoque teórico descriptivo del desarrollo de estos temas, se analiza normativamente la concepción de género inserta en el nuevo Código Penal.

\section{LA NOCIÓN GÉNERO Y LA CONCEPCIÓN DEL DERECHO COMO PRODUCTO Y [RE]PRODUCTOR DE GÉNERO}

Según De Lauretis (2000), la noción de género no solo debe concebirse a través de las diferencias sexuales, sino también, a través de las representaciones lingüísticas y culturales. 
A partir de esta noción, Lucía Núñez establece que: "no se niega la existencia de diferencias anatómicas entre los seres humanos que son materiales y que tienen corporeidad. Lo que se intenta decir, es que tales diferencias siempre se han conceptualizado en oposición una de la otra, lo que ha implicado significarlas de forma desigual" (2018: 32).

La Entidad de la Organización de las Naciones Unidas para la Igualdad de Género y el Empoderamiento de la Mujer (en adelante ONU Mujeres) define género como:

[L]os roles, comportamientos, actividades, y atributos que una sociedad determinada en una época determinada considera apropiados para hombres y mujeres. Además de los atributos sociales y las oportunidades asociadas con la condición de ser hombre y mujer, y las relaciones entre mujeres y hombres, y niñas y niños, el género también se refiere a las relaciones entre mujeres y las relaciones entre hombres. Estos atributos, oportunidades y relaciones son construidos socialmente y aprendidos a través del proceso de socialización. Son especificas al contexto/época y son cambiantes. El género determina qué se espera, qué se permite y qué se valora en una mujer o en un hombre en un contexto determinado (2016).

A partir de los conceptos anteriores, en el género, como se ha dicho, se incluyen los roles, comportamientos y atributos otorgados por la sociedad, por lo tanto, evidentemente el derecho puede constituirse como generador de género, en tanto y en cuanto replique los mismos en el ordenamiento jurídico. Esto ha sido afirmado por Carol Smart (1994), quien presenta al derecho como un derecho sexista, masculino y a su vez creador de género, al exponer que el derecho es productor de identidades que crea y perpetua la significación de género ${ }^{3}$.

Por su parte, Lucía Núñez presupone al derecho como "producto, productor y reproductor de ideología", por lo que, considera necesario estudiar el género como una "representación o autorrepresentación, resultado de diversas tecnologías sociales y discursos institucionalizados". En ese sentido, expone que "el género subsumido en la ideología daría como resultado una ideología de género, la cual tiene como función definitoria sujetos concretos en hombres y mujeres" (2018: 34).

Al subsumir el género en la ideología, se debe hacer notar que, la concepción de ideología es compleja, ya que, como Núñez señala esta se encuentra presente en un universo que incide en las distintas dimensiones de la subjetividad humana y trasciende el género mismo. La autora en mención, ubica a la ideología de género, en las de tipo posicional existencial ${ }^{4}$, al considerar que, esta tiene que

3 Al exponer el derecho como sexista, Smart señala que este enfoque parte de la idea de que, al diferenciar a hombres y mujeres, el derecho pone a las mujeres en desventaja, razón por la que grupos feministas consideran necesario que ante las oportunidades desiguales se debe crear acciones positivas o dar trato preferente como medidas temporales para reequilibrar la balanza. En cuanto al derecho masculino, Smart hace esta consideración a partir de la reflexión en torno a que quienes han construido, interpretado, ejercido y aplicado el derecho, son en su mayoría hombres, lo cual deriva en que los valores y las prácticas masculinas se incorporan al derecho.

4. A partir de los postulados de Therborn, Lucía Núñez cuatro combinaciones posibles de subjetividades: 1) Inclusiva existencial que abarca religiones, mitologías y el discurso moral secular. 2) Inclusiva histórica en la que los individuos se constituyen como miembros conscientes de mundos socio históricos indefinidos como tribus, pueblos, etnias, Estado, nación etc. 3) Posicional existencial que refiere a la posición que tiene un individuo dentro del mundo al que pertenece, en la que 
ver con la forma en la que uno se relaciona con el otro. Núñez señala que "la ideología de género es posicional porque las mujeres, en contraposición con los hombres, ocupan un lugar determinado, una posición inferior. Y es también existencial, ya que ubica a los seres humanos en su existencia como seres sexuados"5. Por lo que, la función de la ideología de género sería: "constituir, modelar $\mathrm{y}$, de esa manera, reproducir la forma en que viven sus vidas, los seres humanos bajo ciertas representaciones desiguales que están ligadas artificialmente a diferencias sexuales concebidas en términos de oposición entre los individuos" (2018: 38).

Siguiendo el desarrollo doctrinal antes expuesto, puede afirmarse, que el Derecho Penal como una de las ramas del Derecho, también es producto, productor y reproductor de género. Es por esta razón que, las posiciones feministas, con respecto a la intervención del Derecho Penal como mecanismo para resolver la problemática de la violencia ejercida contra las mujeres son variadas, aspecto que merece ser analizado previo a estudiar la concepción de género en el Código Penal hondureño.

\footnotetext{
los aspectos más importantes de la estructura de lo dado en la existencia humana son perfilados por las distinciones yo/otros y masculino/femenino, con ello se determina quien es quien en contraposición con los otros.4) Posicional histórico que identifica a los individuos como integrantes de una estructura familiar y de linajes; a los habitantes de una localidad en un modelo amplio geográfico social; a los que gozan de determinado status educativo, ocupacional y estilo de vida y los miembros de diferentes clases.

5 Un aspecto para tener en cuenta es que Nuñez señala que las dimensiones de las subjetividades están empíricamente relacionadas, por lo que, al identificar de la ideología de género como posicional existencial no se busca separarlas sino distinguirlas.
}

\author{
POSICIONES FEMINISTAS CON \\ RESPECTO A LA INTERVENCIÓN \\ DEL DERECHO PENAL COMO \\ MECANISMO PARA RESOLVER EL \\ FENÓMENO DE LA VIOLENCIA \\ CONTRA LAS MUJERES
}

De acuerdo con Elizabeth Schneider (2000), la violencia contra la mujer es un producto del patriarcado y del control masculino. Es por esta razón que, el movimiento feminista es escéptico con respecto al rol del Estado para solucionar dicha problemática a través del Derecho Penal como medio de control social, especialmente, si se tiene en cuenta que aún se lucha por la inclusión de las mujeres en posiciones políticas y de toma de decisiones. Esto es así porque, se tiene la conciencia o se percibe que el Estado refuerza la situación desigual de las mujeres en relación con los demás. Sobre ese particular, los movimientos feministas perciben el rol del Estado como sosteniendo, reafirmando y legitimando dicha violencia en vez de remediarla como correspondería a su rol de garante.

No obstante, son muchos los movimientos feministas que han virado su perspectiva de rechazo del Estado, a una que apoya las reformas legislativas y las posiciones criminalizadoras de la violencia contra la mujer. Elena Larrauri (2018) explica este cambio, al señalar que los grupos feministas aceptan acudir al Derecho Penal como mecanismo para denunciar la gravedad social del problema y consecuentemente, visibilizar las relaciones asimétricas prevalecientes y la subsecuente impunidad. 
Con respecto a las posiciones feministas sobre la intervención del Derecho Penal, Laurrari (2018), identifica en primer lugar, al feminismo oficial, otorgándole la característica de recurrir de forma excesiva al sistema penal, para encontrar respuesta a la problemática social relacionada. En ese sentido, señala que el feminismo oficial exige constantemente el incremento en la duración de las penas, llegando a denominarlo feminismo punitivo. En segundo lugar, al margen del feminismo oficial, la citada autora identifica otros colectivos feministas que denomina progresistas y que se caracterizan por advertir que: "el recurso al sistema penal debe ser excepcional y que cuando se acude a éste las mujeres están más interesadas en la protección que en el castigo" (2018: 69).

En lo referente a recurrir de manera excesiva al Derecho Penal, esta postura ha sido cuestionada porque amplía desmesuradamente el alcance de esta materia y vulnera el principio de intervención mínima. No obstante, esta postura ha sido atacada al considerar que: "la consigna de "derecho penal mínimo" se esgrima sólo cuando las mujeres pretenden introducir algún delito". $\mathrm{Y}$ es que, como bien señala Laurrari: "El principio de "derecho penal mínimo" puede ser usado de forma altamente selectiva si sólo se emplea para criticar la criminalización de algún comportamiento con el cual no se está de acuerdo" (2018: 58).

En cuanto a la posición feminista de incrementar la duración de las penas como mecanismo de disuasión al autor y por ende, para proteger a las mujeres se debe tener en cuenta que, en general en cualquier delito el aumento de la duración de las penas no ha demostrado ser efectivo para la reducción o disuasión de la comisión de una conducta delictiva. Es por esta razón que Laurrari expone:

Exigir, alentar o aceptar mayores penas sabiendo que éstas no contribuyen a disminuir las dimensiones del problema es un ejemplo de populismo punitivo, decir lo (que se cree) que las víctimas quieren oír, y no decir sobre todo cuando se está en la oposición, lo que uno racionalmente cree: que la violencia es un problema complejo, que debe ser abordado con leyes integrales, pero que un ulterior aumento de penas no consigue reducir de forma significativa los delitos (2018: $64)$.

De la misma manera, autoras como Monserrat Sagot Rodríguez (2017), expone una visión integral al señalar que la violencia contra las mujeres es compleja y contingente de muchos factores, lo que requiere cambios y acciones en diferentes niveles ${ }^{6}$, entre estas, normas efectivas para enfrentar en la práctica, la naturaleza y magnitud del problema, así como sus diversas manifestaciones y cortar el

$6 \quad$ Entre los cuales se pueden identificar los siguientes: 1. Construir sociedades más justas e iguales en términos socioeconómicos, pues las estructuras de las múltiples desigualdades (género, raza, clase, edad, etc.) facilitan y promueven el ejercicio de las relaciones de poder y dominio sobre las mujeres; 2. Iniciar procesos para transformar las normas tradicionales de género y fomentar un rechazo a la masculinidad tóxica asociada al control, al honor y a la violencia; 3. Desarticular la violencia masculina a través de respuestas enfáticas y sensibles hacia las víctimas como instituciones que respondan rápidamente y campañas nacionales y locales de repudio a la violencia, difusión de los derechos de las mujeres y 4. Normas efectivas para enfrentar en la práctica, la naturaleza y magnitud del problema, así como sus diversas manifestaciones y cortar el ciclo de la impunidad (2017: 71-73). 
ciclo de la impunidad. Sobre este elemento, Sagot Rodríguez señala que:

[e]l feminismo debe evitar caer en la tentación del carcelarismo, pues solo contribuye a reforzar los poderes represivos del Estado... Sin embargo, también hay que entender que la no criminalización de estas formas de violencia contribuye con la naturalización de los actos y con el desconocimiento de las mujeres como sujetos dignos de justicia (2017: 74).

En cuanto al contexto hondureño uno de los cuestionamientos que hizo el feminismo fue, la reducción significativa de las penas en los delitos relacionados a la violencia contra la mujer. No obstante, este no fue el único, ya que también existió disconformidad de muchos sectores por la falta de inclusión de sus propuestas, por lo que, ha generado la percepción de que es inconsulto e impuesto, característica propia de la dominación masculina que invisibiliza las necesidades de las mujeres y por ende sus voces.

\section{LA INCORPORACIÓN DEL CRITERIO DE GÉNERO COMO REGLA DE INTERPRETACIÓN}

El estudio de La noción de género concebida en el Código Penal inicia con la incorporación del criterio de género como regla de interpretación incluida en el principio de legalidad, establecido en el artículo 1 de la norma penal en estudio. En materia penal, el principio de legalidad se desprende del aforismo nullum crimen, nulla poena sine praevia lege, que como es conocido se traduce "ningún delito, ninguna pena sin ley previa". Santiago Mir Puig (1998) expone que el principio de legalidad es, por un lado, una exigencia de seguridad jurídica que permite tener conocimiento previo de los delitos y las penas $\mathrm{y}$, por otro, una garantía política por medio de la cual no se podrán imponer penas ni medidas de seguridad que no hayan sido aprobadas por el representante del pueblo.

Uno de los aspectos más destacados del principio de legalidad, es que este conlleva el reconocimiento de una garantía criminal, penal, jurisdiccional o judicial y de ejecución. Mir Puig define estas garantías de la forma siguiente:

La garantía criminal exige que el delito (crimen) se halle determinado por la ley (nullum crimen sine lege). La garantía penal requiere que la ley señale la pena que corresponda al hecho (nulla poena sine lege). La garantía jurisdiccional exige que la existencia del delito y la imposición de la pena se determinen por medio de una sentencia judicial y según un procedimiento legalmente establecido. La garantía de ejecución requiere que también la ejecución de la pena se sujete a una ley que la regule. Estas distintas garantías también deben exigirse respecto a las medidas de seguridad y sus presupuestos (1998: 77).

Igualmente, conforme el citado autor, el principio de legalidad impone a la norma jurídica tres requisitos:

1. Lex praevia que expresa la prohibición de retroactividad de las leyes que castigan nuevos delitos o agravan su punición;

2. Lex scripta que excluye la costumbre como posible fuente de delitos y penas, requiriendo una norma escrita emanada del Legislativo como representante del soberano; 
3. Lex stricta que impone un grado de precisión de la ley penal que conlleva a un mandato de determinación que exige se determine una clara diferenciación entre las distintas conductas punibles y a su vez excluye la analogía en cuanto perjudique al reo.

En Honduras, el principio de legalidad de la ley penal se encuentra consagrado constitucionalmente en los artículos 90, 95 y 96. Como se ha señalado, el nuevo Código Penal regula dicho principio en el artículo 1 al prescribir:

Nadie puede ser castigado por acción u omisión que en el momento de su perpetración o comisión no está prevista como delito o falta.

Nadie puede ser castigado con una pena o medida de seguridad que no ha sido previamente establecida por la Ley e impuesta por órgano Jurisdiccional competente conforme a las leyes procesales.

No puede ejecutarse pena ni medida de seguridad de forma distinta a la prescrita por la Ley.

La Ley penal se aplica de forma retroactiva en las disposiciones más favorables al imputado o reo, así como al penado. No obstante, y a no ser que se disponga expresamente lo contrario, los hechos cometidos bajo la vigencia de una ley temporal deben ser juzgados conforme a ella.

La interpretación de este Código se debe realizar conforme al sentido de la Ley y con criterios de género.

Se prohíbe la analogía salvo que beneficie al imputado o reo, así como al penado.

De esta manera, en el nuevo Código Penal por medio de este principio, se exige que, para ejercer el poder punitivo del Estado sobre una persona, se requiere que el delito se encuentre previsto en la ley de manera previa y que la conducta prohibida se encuentre establecida con precisión, al igual que la consecuencia de la transgresión y las penalidades a imponer.

Un elemento que este Código incorpora en el principio de legalidad, es que adicional a la prohibición de analogía propia de este principio $^{7}$, se incorpora el criterio de género como elemento de interpretación. En ese sentido, se debe tener en cuenta la diferencia entre interpretación y analogía. Santiago Mir Puig establece como diferencia que: "mientras que la interpretación es la búsqueda de un sentido del texto legal que se halle dentro de su "sentido literal posible", la analogía supone la aplicación de la ley penal a un supuesto no comprendido en ninguno de los sentidos posibles de su letra, pero análogo a otros sí comprendidos en el texto legal" (1998: 87).

En la aplicación de la ley penal se permite la interpretación siempre y cuando no desborde los límites de esta, es decir, que se mantenga dentro del sentido más literal posible de la norma penal. Por lo que, en el caso de la interpretación con criterios de género que se pueda realizar a partir del citado artículo, no se debe sobrepasar el límite de garantía representado por la literalidad de la ley.

En conclusión, la inclusión del criterio de género como elemento de interpretación del Código Penal es favorable, ya que, con ello se garantiza una aplicación general que visibiliza la desigualdad entre hombres y

7 La analogía en materia penal no es admisible si perjudica al reo (analogía in malam partem), no obstante, no choca con el límite garantizador que posee el texto legal cuando favorezca al reo (analogía in bonam partem). 
mujeres y no solo en los delitos relacionados a la violencia contra las mujeres. No obstante, la nueva normativa no establece que deberá entenderse por "criterio de género" lo que podría conllevar a la discrecionalidad de las y los operadores de justicia o lo que es peor, no aplicarlo. Por lo que, resulta necesario ampliar, en este precepto o en otro, lo que debe entenderse por criterio de género, para permitir una correcta aplicación de dicha figura.

\section{LA DISCRIMINACIÓN COMO CIRCUNSTANCIA AGRAVANTE QUE MODIFICA LA RESPONSABILIDAD PENAL}

El nuevo Código Penal regula en el artículo 32 numeral 8 la discriminación como circunstancia agravante, de la forma siguiente: "Cometer el delito por motivos racistas u otros relativos a la ideología, religión o creencias de la víctima, edad, lengua, situación familiar, etnia, raza o nación a la que pertenezca, su sexo, orientación sexual o identidad de género, razones de género, enfermedad o discapacidad."

Esto se encuentra en consonancia con el artículo 60 de la Constitución de la República que establece la igualdad como derecho y la discriminación como su correlato, en los términos siguientes:

Todos los hombres nacen libres e iguales en derechos. En Honduras no hay clases privilegiadas. Todos los hondureños son iguales ante la Ley. Se declara punible toda discriminación por motivo de sexo, raza, clase y cualquier otra lesiva a la dignidad humana. La Ley establecerá los delitos y sanciones para el infractor de este precepto.
Doctrinalmente, la circunstancia agravante de discriminación se considera una condición subjetiva que indica una motivación particularmente indeseable que se intenta evitar a través de la legislación penal (Mir Puig, 1998: 645). La inclusión de la agravante de discriminación en el nuevo Código Penal resulta positiva, al incluir la discriminación basada en razones de género, ampliando de esta manera, la protección penal hacia las mujeres y niñas. Con la inclusión de la agravante de discriminación basada en razones de género, el incremento de la pena no solo es aplicable a los delitos que expresamente lo contengan en la descripción típica del delito ${ }^{8}$, sino que, en todos los casos en lo que se presenten relaciones desiguales de poder caracterizadas por la intención de dominación del hombre sobre la mujer.

La CEDAW define "discriminación contra la mujer" como:

[t]oda distinción, exclusión o restricción basada en el sexo que tenga por objeto o resultado menoscabar o anular el reconocimiento, goce o ejercicio por la mujer, independientemente de su estado civil, sobre la base de la igualdad del hombre y la mujer, de los derechos humanos y las libertades fundamentales en las esferas política, económica, social, cultural y civil o en cualquier otra esfera.

La inclusión de la agravante de la discriminación por razones de género de forma 8 Además de los delitos regulados en el Título $\mathrm{V}$ relacionados a la violencia contra la mujer, así como los delitos de violencia sexual que incluyen como agravante las cometidas en contex tos de violencia de género, el nuevo Código Penal incluye en la descripción típica de algunos delitos aspectos de género, ejemplo de ello, es el delito de discriminación laboral (Art.295); quebrantamiento de condena o medida (Art.526); Crimenes de lesa humanidad (Art. 139); Tipos agravados de lesiones (Art.200); Denegación de presentación de un servicio público (Art. 211). 
general, es favorable sobretodo si se toma en cuentala existencia de una nueva conflictividad informal y guerras no convencionales en América Latina conformadas por el accionar del crimen organizado, las guerras represivas para-estatales de los regímenes dictatoriales, con sus fuerzas para-militares o sus fuerzas de seguridad oficiales actuando para-militarmente; la represión policial y el accionar represivo y truculento de las fuerzas de seguridad privada, que conllevan al incremento de la violencia, planteado por Rita Segato (2014).

Sobre esta nueva forma de guerra, la citada autora señala que, esta violencia se expresa de forma privilegiada en el cuerpo de las mujeres a través de la violencia ejecutada por medios sexuales donde se afirma la destrucción moral del enemigo. De esta manera, Segato señala que: "el cuerpo de la mujer es el bastidor o soporte en que se escribe la derrota moral del enemigo" (2014: 23). En este tipo de contextos de violencia, el cuerpo de la mujer es considerado un cuerpo frágil, por lo que, el atacarlo representa "un mensaje de ilimitada capacidad violenta y de bajos umbrales de sensibilidad humana" (2014: 23), que en algunos casos se extiende a niños y jóvenes. En este contexto, la referida autora advierte que este tipo de violencia, si bien es cierto, difiere a los crímenes de género, los mismos mantienen los elementos centrales de la configuración de la estructura patriarcal.

Este contexto de violencia denominada "conflictividad informal o guerra no convencional" no es ajena a la realidad hondureña. Según el Observatorio de la
Violencia del Instituto Universitario en Democracia, Paz y Seguridad (en adelante IUDPAS):

La tasa de homicidios en Honduras para 2018 fue de 41.4 (pccmh) y pese a la reducción de 2.2 puntos en comparación al 2017, el riesgo se mantiene en niveles epidémicos cinco veces más altos que el estándar mundial establecido por la OMS (8.8). En los últimos 15 años se han registrado 71,695 homicidios. Entre 2004 y 2011 los homicidios mantuvieron un ascenso sostenido y en 2011 se llegó a la tasa más alta (86.5) del ciclo analizado. A partir de 2012 las cifras empezaron a disminuir, de 2016 a 2017 se registró el mayor descenso del periodo con una reducción de 15.5 puntos en la tasa de homicidios (2019: 4).

Es en este contexto, que el Observatorio de Muertes Violentas de Mujeres y Femicidios del IUDPAS ha identificado los femicidios por delincuencia organizada señalando que: "los femicidos por delincuencia organizada representan el 37.2\% del total de femicidios ocurridos en el país durante 2018". Y es que, debido al contexto hondureño, los delitos que se den en estos ámbitos deberán entenderse como actos que mantienen los elementos de las estructuras patriarcales.

En resumen, la inclusión de la agravante de discriminación por razones de género en el Código Penal es favorable, ya que la desigualdad en las relaciones de poder entre hombres y mujeres no son exclusivas a los tipos penales contemplados en el Título sobre la violencia contra las mujeres, al presentarse este en diferentes escenarios. 


\section{LA TIPIFICACIÓN DE LOS DELITOS CONTRA LAS MUJERES COMO PRODUCTO DEL GÉNERO}

Una de las manifestaciones del género nace desde el momento mismo de la creación de los tipos penales. El Derecho Penal se basa en la invocación de lo que no debe ser a través de la prohibición, determinando una noción de bien y mal que se traduce en conductas correctas e incorrectas. De esta manera, a partir de la prohibición se crea una exclusión de actos (acciones u omisiones) que se consideran no adecuados a la vida social. Con la determinación de actos prohibidos también se establecen sujetos diferenciados, como, por ejemplo, hombres y mujeres, que son percibidos a partir de definírseles como sujetos sexuados.

De esta manera, Lucia Núñez postula que es, en la elaboración de las normas que se produce la ideología de género y la perpetuación de relaciones desiguales de género al afirmar:

$\mathrm{El}$ acento se pone en la elaboración de las normas y en la regla misma, en virtud de que es a partir de esta que se logra configurar la hipótesis aquí desarrollada; es decir, la (re)producción de determinada ideología de género y su función en la constitución de subjetividades discursivas con el objeto de resaltar el papel del código penal (definición legal) en la creación y perpetuación de relaciones desiguales de género (2018: 63).

Por lo anterior, se puede afirmar que la normativa penal establece una diferencia entre hombre y mujer como cuerpos sexuados. Esta noción se hace evidente cuando nos referimos a la capacidad de reproducción de las mujeres y el control que se ejerce sobre el cuerpo de la mujer a partir de la concepción de que su cuerpo está relacionado con los procesos de vida.

Un claro ejemplo, es la sanción establecida en el artículo 196 con penas de duración de hasta 10 años ${ }^{9}$, impuesta a la mujer -e incluso a la niña como un acto justiciable a través del Sistema de Justicia Penal Juvenil- cuando se practique un aborto. La prohibición absoluta del aborto, atenta contra los derechos de las mujeres, ya que, como bien señalara la Relatoría Especial sobre la Tortura y otros Tratos o Penas crueles inhumanas y degradantes:

El aborto practicado en condiciones de riesgo ocupa el tercer lugar entre las principales causas de muerte materna en todo el mundo. Cuando el aborto está restringido por ley, la mortalidad materna aumenta, pues las mujeres se ven obligadas a someterse a abortos clandestinos en condiciones peligrosas y antihigiénicas. También aparecen consecuencias físicas y psicológicas a corto y largo plazo cuando las mujeres se someten a abortos en condiciones de riesgo y cuando se ven obligadas a llevar el embarazo a término contra su voluntad (A/66/254). Estas políticas restrictivas tienen unas

9 Artículo 196. ABORTO. El aborto es la muerte de un ser humano en cualquier momento del embarazo o durante el parto. Quien intencionalmente cause un aborto debe ser castigado: 1) Con tres (3) a seis (6) años de prisión si la mujer lo hubiere consentido o produzca su aborto; 2) Con seis (6) a ocho (8) años de prisión si el agente obra sin el consentimiento de la embarazada y sin emplear violencia o intimidación; y, 3) Con ocho (8) a diez (10) años de prisión si el agente emplea violencia, intimidación o engaño. Además de las penas señaladas en los numerales anteriores, a los profesionales sanitarios que abusando de su profesión causen o cooperen en la realización del aborto, se les impondrá también, la pena de multa de quinientos (500) a mil $(1,000)$ días. Quien por actos de violencia ocasiona el aborto sin el propósito de causarlo, pero constándole el estado de embarazo de la víctima, debe ser castigado con la pena de prisión de ocho (8) a diez (10) años, sin perjuicio de la pena que corresponda por los actos de violencia que realice. 
repercusiones desproporcionadas en las mujeres y niñas marginadas y desfavorecidas. La existencia de leyes muy restrictivas, que prohíben los abortos incluso en casos de incesto, violación, deficiencia fetal o cuando está en riesgo la vida o la salud de la madre, vulneran el derecho de las mujeres a no ser sometidas a tortura o malos tratos (2016: 13).

La prohibición absoluta del aborto en el nuevo Código Penal fue objeto de cuestionamiento por diversos sectores y grupos feministas durante el proceso de discusión y aprobación en el Congreso Nacional. En general, sus exigencias se podrían resumir en lo expuesto por el Centro de Derechos de Mujeres:

ElnuevoCódigoPenaldebemantenerlapenalización del aborto cuando este no es consentido por la mujer embarazada como una forma de proteger la dignidad humana y la libertad reproductiva. Sin embargo, también debe atender a: (i) las diversas recomendaciones al Estado de Honduras para que el aborto se despenalice al menos por 3 causales: en casos de violación, en casos de malformación fetal incompatible con la vida, o cuanto la vida o la salud de la mujer embarazada se encuentre en riesgo y; (ii) atendiendo a la tipificación de tortura, tratos crueles, inhumanos y degradantes realizada por el nuevo Código Penal en consideración de que la Relatoría Especial sobre la Tortura y otros Tratos o Penas crueles, inhumanas y degradantes ha determinado que las consecuencias de llevar un embarazo no deseado a término vulneran el derecho de las mujeres a no ser sometidas a tortura o tratos crueles, inhumanos o degradantes (2020: 8).

El Congreso Nacional de la República hizo caso omiso delas recomendaciones formuladas al Estado de Honduras en la materia por los diferentes mecanismos y procedimientos temáticos tanto de las Naciones Unidas como de la Organización de Estados Americanos y a las exigencias de las diferentes organizaciones de promoción y protección de los derechos de la mujer y grupos feministas. Al final resultó, una nueva normativa que refuerza la noción sexista entre hombre y mujer y a su vez, las desigualdades en las relaciones entre éstos. Lo anterior debido a que, invisibiliza sus exigencias y necesidades resultando que como bien expone Teresa De Lauretis:

El feminismo descubrió la inexistencia de la mujer o, mejor dicho, la paradoja de un ser que está ausente y a la vez prisionero del discurso, sobre quien se discute constantemente pero permanece, de por sí, inexpresable; un ser espectacularmente exhibido, pero a la vez no representado o irrepresentable, invisible, pero constituido como objeto y garantía de la visión: un ser cuya existencia y especificidad al mismo tiempo se afirman y niegan, se ponen en duda y se controlan (2011: 11).

A partir de lo anterior, se concluye al incluir en el nuevo Código Penal la prohibición absoluta del aborto, el Estado asume un doble discurso en cuanto al género. Por un lado, incorpora de manera favorable como criterio de interpretación de la norma penal, "el género", y, por otro lado, hace caso omiso, a las propuestas de organizaciones y grupos feministas al momento de crear la norma y al incluir la prohibición absoluta del aborto, reproduciendo con ello, una visión sexista y a su vez patriarcal de control sobre el cuerpo de la mujer. En consecuencia, negando el derecho de las mujeres a ser partícipes y decisoras en temas que atañen a su vida y sexualidad. 
La inclusión de la prohibición absoluta del aborto responde esencialmente a que Honduras se caracteriza por ser una sociedad eminentemente conservadora que, a su vez, se basa en estructuras patriarcales y estereotipos en los comportamientos y roles de cada sexo. Desde el análisis de la concepción del aborto en el nuevo Código Penal, resulta cuestionable el alcance descriptivo del "género como criterio de interpretación" insertado en el principio de legalidad, ya que, podría afirmarse que el mismo únicamente fue incluido esencialmente desde una visión política, con el propósito de crear una normativa con la que pudieran estar de acuerdo las destinatarias de la norma (mujeres como sujetas de derecho y a la vez víctimas). Con ello, las y los legisladores reproducen y producen género, manteniendo al momento de crear la norma las relaciones desiguales de poder entre hombres y mujeres. En otras palabras, se legisló obligando a juzgar con criterio de género, sin haberse legislado con enfoque de género.

Otra de las incorporaciones que realiza el Código Penal es la de los delitos relacionados con la violencia contra la mujer contenidos en el Titulo $\mathrm{V}$, en el que se regulan dos conductas típicas: el femicidio y la violencia contra la mujer.

La Convención Belém do Pará en el artículo 1 define la violencia contra las mujeres como: "cualquier acción o conducta, basada en su género, que cause muerte, daño o sufrimiento físico, sexual o psicológico a la mujer, tanto en el ámbito público como en el privado". Por su parte, el artículo 2 reconoce 3 tipos de violencia contra las mujeres: La violencia física, sexual y psicológica; visibilizando que estas pueden presentarse en la vida privada, la vida pública y la perpetrada o tolerada por el Estado ${ }^{10}$.

Marcela Lagarde y de los Ríos (2012), plantea la incorporación por parte de un grupo de legisladoras en la Ley General de Acceso de las Mujeres a una Vida Libre de Violencia en México de todos los tipos y modalidades de violencia de género contra las mujeres, los cuales coloca en el ámbito del delito y entre los que se encuentran la violencia: a) física, b) sexual, c) psicológica, d) económica, y, e) patrimonial. En cuanto a las modalidades, estas se definen a partir del ámbito en que ocurre: a) familiar, b) en la comunidad, c) laboral y educativa, d) institucional, y, e) feminicida.

La inclusión en la ley penal hondureña de estos tipos penales es favorable, ya que, a través de este se gesta una herramienta que protege el derecho de las mujeres a vivir una vida libre de violencia y a su vez, visibiliza la desigualdad en las relaciones entre hombres y mujeres.

No obstante, el Derecho Penal puede ser desigual en cuanto a considerar la protección normativa de determinados bienes jurídicos

10 Artículo 2. Se entenderá que violencia contra la mujer incluye la violencia física, sexual y psicológica: a. que tenga lugar dentro de la familia o unidad doméstica o en cualquier otra relación interpersonal, ya sea que el agresor comparta o haya compartido el mismo domicilio que la mujer, y que comprende, entre otros, violación, maltrato y abuso sexual; b. que tenga lugar en la comunidad y sea perpetrada por cualquier persona y que comprende, entre otros, violación, abuso sexual, tortura, trata de personas, prostitución forzada, secuestro y acoso sexual en el lugar de trabajo, así como en instituciones educativas, establecimientos de salud o cualquier otro lugar, y c. que sea perpetrada o tolerada por el Estado o sus agentes, donde quiera que ocurra 
de personas colocados en posición de vulnerabilidad, lo que se ve reflejado en las muertes violentas de mujeres trans. Al respecto, no fue incluida la demanda de la Red Lésbica Cattrachas, que ha exigido la tipificación del transfemicidio. De esta manera, Cattrachas expone:

En el caso particular de los asesinatos de mujeres trans, es necesario que sea tipificado el delito de transfemicidio como una nueva configuración penal que refleje dentro de sus elementos subjetivos, el tipo especialísimo de violencia género motivada por el prejuicio, el desprecio y la discriminación del género y la identidad asumida de las víctimas y el hecho de ser mujeres trans (2019: 12).

Sobre este aspecto, cabe citar a Elena Larrauri quien afirma que: "el derecho penal se demora al incorporar determinadas voces que carecen de poder y no es igualitario en la protección de todos los bienes jurídicos, pues la visibilidad de estos también depende del poder que tiene el grupo social afectado" (2018: 70). El no reconocimiento en la normativa penal de la muerte violenta de mujeres trans, como un tipo penal especial cualificado por el resultado responde a una forma de legislar basada en estereotipos de comportamientos y roles de cada sexo, que no otorga reconocimientos a estas identidades ni ninguna forma de poder e influencia a estos grupos colocados en posición de vulnerabilidad, reforzando con ello, lo que se espera, permite y valora en una mujer o en un hombre. Esta actitud omisiva también crea "género" al ignorar la violencia motivada por el desprecio del género asumida por las mujeres trans.
En cuanto al delito de violencia contra mujeres, la incorporación de este también resulta favorable, ya que, incorpora en la normativa penal la violencia física o psíquica que se produzca en el marco de relaciones desiguales de poder entre hombres y mujeres basadas en género. No obstante, los grupos feministas del país han considerado que la misma es restringida con respecto a los tipos de violencia hacia las mujeres ${ }^{11}$.

Finalmente, es de hacer notar que, el Título referente a la violencia contra la mujer establece lo que, para efectos de ese Título, deberá entenderse por relaciones desiguales de poder basados en el género entre hombres y mujeres señalando: "cuando la muerte o violencia aparece como una manifestación de discriminación hacia la mujer por el hecho de serlo, haya o no una relación previa entre agresor y víctima y con independencia de que se produzca en un contexto público o privado".

Sobre esta concepción es importante señalar que, si bien la violencia contra las mujeres es general, no todas están expuestas al mismo nivel de riesgo. Actualmente, se ha desarrollo el análisis interseccional que aborda la violencia contra las mujeres considerando la clase social, etnia, raza, edad, sexualidad, etc. que se intersectan con el género para producir formas diferenciadas $11 \mathrm{El}$ Centro de Derechos de Mujeres con respecto al delito de violencia contra mujeres apunta que: "Las violencias contra mujeres se expresan de múltiples maneras. El Código Penal restringe la violencia a violencia física o psíquica”. Por consiguiente: "El tipo penal de violencia contra la mujer debe incorporar la violencia patrimonial como un tercer tipo de violencia igualmente condenable. Así mismo y como en el tipo penal de femicidio, se debe considerar como circunstancia agravante si la mujer víctima cuenta con una condición de mayor vulnerabilidad". 
de desigualdad, que por supuesto, agravan los riesgos y vulnerabilidades a las que la mujer se encuentra expuesta.

Con respecto a la interseccionalidad en la violencia contra mujeres, Montserrat Sagot expone:

El análisis interseccional ayuda, justamente, a entender cómo esas formas diferenciadas de desigualdad crean diferentes condiciones de riesgo y peligrosidad para las mujeres, cómo la violencia es experimentada por mujeres particulares, cómo responden otros a esa violencia y qué posibilidades tienen las mujeres de vivir con alguna seguridad dependiendo de su posición en esa intersección de múltiples sistemas de opresión. Es decir, el tipo de violencia que se vive, su severidad, las posibilidades de conseguir ayuda y de sobrevivir y de que el crimen no quede impune, varían de forma considerable de acuerdo con las características de la mujer afectada, del perpetrador y del propio contexto (2017: 64).

En ese sentido, la autora en referencia, considera necesario que la violencia contra las mujeres incorpore una perspectiva interseccional que reconozca el lugar diferenciado de cada mujer y que garantice mayor seguridad ante las diferentes formas y manifestaciones de opresión que puedan presentarse. Teniendo en cuenta que, las mujeres provenientes de los sectores o grupos más excluidos por razones de raza, clase, edad, sexualidad u otra condición análoga enfrentan mayores peligros y riesgos que fácilmente llegan a traducirse en violencias extremas de género.

Como se apuntó, el nuevo Código Penal, al regular la violencia contra la mujer no incorpora una perspectiva interseccional, con lo que, se desconoce las diferentes posiciones de vulnerabilidad en los que la mujer se encuentra ante la violencia de género. Este aspecto debió ser incorporado en dicho Título al momento de regular en la Disposición Común, lo que se debe entenderse por relaciones desiguales de poder entre hombres y mujeres.

Otra forma de violencia contra la mujer es la violencia sexual, que se encuentra regulada fuera de los delitos específicos a la violencia contra la mujer, al tratarse de delitos que no afectan exclusivamente a las mujeres, aunque, cabe destacar que, regula como agravante de dichas conductas las realizadas en contexto violencia de género. El nuevo Código Penal tipifica la violencia sexual a través del delito de violación (art. 249), incesto (art. 252), contacto con finalidad sexual con menores por medios electrónicos (art. 253), estupro (art. 254) y hostigamiento sexual (art. 256).

Sobre estos delitos, los elementos descriptivos del incesto ${ }^{12}$ y el estupro ${ }^{13}$ resultan perjudicial pues no se protege debidamente a los bienes jurídicos comprometidos. En cuanto al incesto, este delito no toma en cuenta que

12 ARTÍCULO 252.- INCESTO. Quien tiene acceso carnal con su descendiente, hermano o sobrino que sea mayor de catorce (14) y menor de dieciocho (18) años, debe ser castigado como autor de un delito de incesto con las penas de prisión de cuatro (4) a seis (6) años, salvo que el hecho deba ser castigado más gravemente conforme a otro precepto del presente Código. 13 ARTÍCULO 254.- ESTUPRO. Quien utilizando engaño realiza actos de contenido sexual con persona mayor de catorce (14) y menor de dieciocho (18) años, debe ser castigado con la pena de prisión de seis (6) meses a un (1) año. Si los actos sexuales implican acceso carnal por cualquier vía, las penas deben ser de prisión de uno (1) a tres (3) años y prestación de servicios de utilidad pública o a las víctimas por tiempo de dos (2) a cuatro (4) meses o multa de trescientos (300) a seiscientos (600) días. 
gran parte de las violaciones sexuales contra niñas, niños y adolescentes se dan en el seno familiar. Por lo que, al regular la conducta incestuosa esta no guarda armonía con la pena que correspondería con el delito de violación sexual, lejos de eso la pena se atenúa, por ende, el daño a la víctima no se corresponde con la pena impuesta. Por su parte, el estupro, al contemplar como elemento del delito el consentimiento utilizando el engaño ha sido solicitado por grupos feministas que el mismo se regule como una modalidad de violación especial ${ }^{14}$, aspecto que no sucede en el nuevo Código Penal. Al contrario, al regularse como una conducta separada de la violación sexual se reduce la pena a aplicar al agresor.

De esta manera, se concluye que el nuevo Código Penal a pesar de incluir el criterio de género como regla de interpretación, el mismo reproduce y produce comportamientos, actividades y atributos que la sociedad considera apropiados para hombres y mujeres. Por lo que, refleja los estereotipos culturales que existen respecto a los comportamientos referidos a cada sexo, propio de estructuras patriarcales que marcan diferencias $y$ desigualdades entre mujeres y hombres.

No obstante, es importante que al momento de aplicar la norma y utilizando el criterio de género como regla de interpretación

14 El Centro de Derechos de Mujeres al respecto ha señalado: "El delito de estupro comprende dos situaciones: - Una agresión sexual sin acceso carnal no consentida contra una persona entre 14 y 18 años o; - El acceso carnal que ocurra mediante engaño o prevaliéndose de una situación de superioridad manifiesta. Ambas situaciones corresponden a modalidades ya contempladas previamente en el Código Penal. Por un lado, el estupro debe considerarse como un caso especial de violación, con un castigo de penas privativas de libertad y multas, bajo la figura de violación. Y por otro lado, las agresiones sexuales no consentidas deben considerarse bajo la figura de Otras Agresiones Sexuales.” establecido en el artículo 1, la o el juzgador analice los sesgos implícitos en la normativa penal. En países como México, la Suprema Corte de Justicia de la Nación adoptó el Protocolo para Juzgar con Perspectiva de Género, acción que sería loable de imitar por parte de la Corte Suprema de Justicia en Honduras. Ello, brindaría un apoyo y guía para las y los jueces con respecto al criterio de género como regla de interpretación ${ }^{15}$, que permitiría considerar la aplicación en el caso concreto de la doctrina, jurisprudencia y estándares internacionales en la materia, principalmente a través del control de convencionalidad.

\section{CONCLUSIONES}

El nuevo Código Penal introduce de manera novedosa, el criterio de género como regla de interpretación, pero en su contenido general reproduce los roles, comportamientos

15 El Protocolo en mención considera 4 etapas como parte del proceso argumentativo que deriva en una sentencia o resolución: Determinación de los hechos e interpretación de la prueba; establecimiento del derecho aplicable; argumentación; y, reparación del daño. En dichas etapas se incluyen diversos elementos a considerar como los que se resumen a continuación: • Determinación de los hechos e interpretación de la prueba: Establece una serie de preguntas que deberá realizar la o el juzgador para evitar la valoración estereotipada del comportamiento de las personas involucradas, así como por la consideración que se haga del contexto en que se dio el hecho o el acto jurídico. • Determinación del derecho aplicable: Se incluye la necesidad de incorporar un enfoque interseccional; el uso del soft law, entre otros. - Argumentación: Implica el realizar una interpretación protectora que garantice el respeto a la dignidad humana; el criterio hermenéutico de interpretación pro persona encaminado a un sistema interpretativo que favorezca la aplicación de tratados internacionales cuando favorezca a la persona; el uso de sentencias que se hacen cargo de estereotipos basados en el sexo y los roles sexuales; reconocer y evidenciar los sesgos de género a través de los criterios interpretativos de una sentencia; y, evitar la revictimización. Reparación del daño: La adopción de esfuerzos para que las medidas de reparación integral obedezcan un enfoque transformador que contribuyan a la eliminación de esquemas de discriminación y marginación. 
y atributos considerados apropiados para hombres y mujeres, generando desde lo normativo, desigualdades en las relaciones y oportunidades entre estos.

Una de las formas en que este Código se manifiesta como "producto, reproductor y productor de género", es por medio de la incorporación de la prohibición absoluta del aborto, respondiendo a una visión patriarcal de control sobre el cuerpo de la mujer, además que ignora el derecho de participar de las mujeres en temas directamente relacionados con su vida y devenir invisibilizando su voz y consecuentemente negándole sus derechos.

Además, la incorporación de este tipo es contraria a las diversas recomendaciones formuladas al Estado de Honduras por organismos internacionales de derechos humanos, que consideran tal prohibición como una práctica lesiva a la integridad e indemnidad sexual de la mujer, ya que, los abortos practicados en condiciones de riesgo es una de las principales causas de muerte materna en el mundo.

La inclusión del Título relativo a los delitos de violencia contra la mujer es favorable al visibilizar la problemática social a través de la ley penal. Sin embargo, no se tomaron en cuenta las demandas para la incorporación de determinados tipos penales como el transfemicidio. La no inclusión de estos tipos ya sea como delitos o como circunstancias especiales en el femicidio responde a la reafirmación de las conductas, atributos y comportamientos socialmente considerados apropiados para hombres y mujeres, que a su vez refuerzan las desigualdades entre tales.
Este Código define las relaciones desiguales de poder basados en el género sin perspectiva interseccional, por lo que, no reconoce las condiciones de riesgo, peligrosidad y vulnerabilidad de cada mujer, por condiciones de raza, edad, clase, sexualidad, localización geográfica, etc.

Este Código Penal asume un doble discurso en cuanto al género. Por un lado, incorpora de manera favorable el criterio de género como regla de interpretación y la discriminación por razones de género como circunstancia agravante y, por otro lado, se legisló sin un enfoque de género, creando tipos penales en sentido contrario, además de negar el derecho de las mujeres a ser participes y decisoras en temas que atañen a su vida mediante su intervención en el proceso de discusión y aprobación.

El Congreso Nacional de la República reproduce y produce el género, al crear el nuevo Código Penal manteniendo relaciones desiguales de poder entre hombres y mujeres. En otras palabras, se legisló obligando a juzgar con criterio de género, sin haber legislado con enfoque de género.

\section{BIBLIOGRAFÍA.}

Laurrauri, Elena. Criminología crítica y Violencia de Género. Editorial Trotta. Segunda Edición. Madrid. 2018.

Lagarde y de los Ríos, Marcela. El feminismo en mi vida, Hitos, claves y topías. Instituto de las Mujeres del Distrito Federal. México DF. 2012. 
Sagot Rodríguez, Monserrat, coord. (et. al). Feminismos, pensamiento crítico y propuestas alternativas en América Latina. CLACSO. Buenos Aires. 2017.

Segato, Rita Laura. Las nuevas formas de la guerra y el cuerpo de las mujeres. Pez en el árbol. México DF. 2014.

Smart, Carol. 1994. La mujer del discurso jurídico en L. Nuñez, El género en la ley penal: Crítica feminista de la ilusión punitiva. Centro de Investigaciones y Estudios de Género.

Instituto Universitario en Democracia, Paz y Seguridad (IUDPAS). Boletín Mortalidad y Otros, enero - diciembre 2018. Edición No. 52. 2019.

Informe del Relator Especial sobre la tortura $\mathrm{y}$ otros tratos o penas crueles, inhumanos $\mathrm{o}$ degradantes. A/HRC/31/57. 31 período de sesiones. 5 de enero de 2016.

Observatorio de Derechos Humanos de las Mujeres, Centro de Derechos de Mujeres (CDM). El nuevo Código Penal y los derechos humanos de las mujeres en Honduras. Mayo 2020.

Red Lésbica Cattrachas. Informes Alternativos III Examen Periódico Universal, temática LGBTI \& LGTBI-VIH Honduras. Octubre 2019. Disponible en: https://cattrachas. org/images/archivos/informes-alternativosEPU-SOGI-y-SOGI-VIH-CattrachasHonduras.pdf
Cepal.org. Observatorio de Igualdad de Género de América Latina y el Caribe. Disponible en: https://oig.cepal.org/es/ indicadores/feminicidio.

UnWomen.org. Concepts and definitions. Disponible en: https://www.un.org/ womenwatch/osagi/conceptsandefinitions. $\underline{\text { htm. }}$. 